\title{
Classroom Interaction Analysis in Ethiopian EFL Speaking Class: Feedback, Interactional Strategies, and Interaction-Oriented Speaking Inputs Through Descriptive Qualitative Design
}

Sisay Ayalew Tsegaw ( $\square$ lesisay12@gmail.com)

Bahir Dar University

\section{Research Article}

Keywords: classroom interaction, feedback, interactional strategies, inputs, questioning, pattern

Posted Date: March 2nd, 2022

DOI: https://doi.org/10.21203/rs.3.rs-1373060/v1

License: (c) (i) This work is licensed under a Creative Commons Attribution 4.0 International License. Read Full License 


\section{Abstract}

The major goal of this study was to explore classroom interaction by using Interaction Analysis Categories System in teaching speaking skills for grade nine students. A qualitative research method, particularly descriptive qualitative design, was employed under the pragmatism research paradigm to achieve the study's objectives. The target populations of the study were Lalibela secondary school, all grade nine English language teachers together with their respective selected sections of students. The study's participants were chosen using a purposive sampling technique. This study included four teachers as well. Data were collected through observation, teacher interviews, and documents. A qualitative method of data analysis was carried out to analyze the data collected through the data collection instruments. Correspondingly, Walsh's (2006) Self Evaluation of Teacher Talk (SETT) data analyzing tool was adopted as the observation protocol to characterize teacher-student interaction for emerging themes and findings of the study. The study's finding revealed that teachers were excessively used display questions and formfocused feedback. The results showed that the most frequent interactional strategies were a single, extended teacher turn with explanations/instruction and patterns of Non-IRF. On the other hand, in student talks, the utterances of restricted reply and students' elicits were more dominant. Teachers did not deliver a few interactive activities appropriately in accordance with this. Finally, recommendations were forwarded regarding providing the types of questions and feedback, teachers' appropriate use of interactional strategies, arousing students' interest, and delivering interaction activities in exploring classroom interaction of EFL in developing speaking skills.

\section{Introduction}

Language is important in many aspects of life. It's possible that the world would not be what it is now if it hadn't happened. Learning a language, on the other hand, is not as simple as it appears. This is because learning a language necessitates a thorough understanding of the linguistic system (grammar, vocabulary, etc.) as well as its application (the skills). Discussion and engagement can engage and promote students' creativity, comprehension, and imagination. Students use speaking to solve issues, speculate, discuss ideas, make decisions, and reflect on what is important in their everyday lives; speaking skills are now significant in language programs all around the world (Richard, 2001). Therefore, this is a good moment to study the current assumptions and practices concerned with teaching these crucial speaking skills.

In my teaching experience, students have trouble speaking English fluently even if they graduate from secondary schools. Thus, this study explored the possible poor interactions and causes of why students did not talk in and out of classes and find solutions. Additionally, speaking skills are neglected when we see our classroom contexts and recorded low results in most language classrooms. Besides, in Lalibela secondary school, where the present researcher works, students were limited to engaging themselves in speaking tasks since they had little experience in primary school. Consequently, this could be attributed to students' low speaking proficiency. As an illustration, when the researcher analyzed the students' speaking skills result of 2011 E.C, $69 \%$ of the students scored below 41 out of 100. Therefore, the present researcher proposed that classroom interaction was one issue that needs to be deeply explored in this EFL setting, given its significance in creating a productive environment for students' learning and development.

Some previous studies have related classroom interactional strategies and feedback in speaking class. Suryati (2015), for example, conducted research on teachers' use of interaction strategies in English Language Teaching (ELT) at the lower secondary level. The findings of Suryati's study revealed that much of the teacher-student interaction in lower secondary schools centred on material, skill, and system modes. Initiation response feedback (IRF) patterns, display questions, instructor echo, and extended teacher turns were the most common strategies, whereas students' extended turns were rare. The findings also show that teachers spent $93 \%$ of their teaching time on teacher-student interaction and $7 \%$ on student-student interaction. Suryati added that, during teacher-student interaction, the most popular interaction strategies are asking display questions (38\%), teacher extended turns (27.2\%), teacher echoes (17.3\%), giving form-focused feedback (7.9\%). Because there are 629 IRF patterns in total, they dominate teacher-student interaction, while non-IRF patterns only have 99 occurrences.

I intended to study feedback during classroom interactions since the teacher's oral corrective feedback is always debatable and open for investigation for many scholars who have doubts about whether it is beneficial to language development and speaking skill enhancement. The present researcher believes that a teacher's oral corrective feedback impacts students' speaking abilities 
and leads to improved achievement or the students' ability to improve their speaking skills. In addition, it enables them to increase their language store, to have the opportunity to understand and to use the incomprehensible language, to help them learn the target language easily and quickly (Liu et al., 2010) through the teacher's oral corrective feedback.

Rafieerad and Rashidi (2010) have performed research into the pattern of classroom interaction in Iranian EFL courses. Despite the fact that classroom discourse follows the IRF (initiation-response-feedback) pattern, they discovered that the teacher dominated a large percentage of the conversation. The pupils exchanged information with the teacher. They followed up on their teacher's responses to their queries, demonstrating that the teacher used an IRF pattern to deliver the students' teacher talk. Tsui (2003) also studied patterns and perspectives from secondary school junior students. According to the data, $70 \%$ of the turns taken in a classroom discourse were teacher-initiated, and $16 \%$ were teacher-respond.

Whereas, Pupil-Initiate and pupil-respond found $2 \%$ and $12 \%$, respectively. Yes or no questions took up the most significant part of eliciting teacher-initiated questions, followed by factual questions, while explanation questions were least found. In addition, the teacher-elicit took many turns. In contrast, the frame was last seen in teacher initiate. Accept, and Comment were most commonly found in teachers' responses. In pupil talk, elicit and Interrupt each took up the highest percentage of pupil initiate. However, restricted replies were found to take up the most significant portion of pupil response.

In Ethiopia, only relatively scant studies are conducted by combining the various aspects of the variables considered in this study: Teacher questioning, interactional strategies, and feedback. Markedly, several researchers have dealt with the different aspects of classroom interactions. Many Ethiopian researchers have concentrated on such areas of interest, such as attitude, practice implementation or methods, factors, strategies, assessment, and achievement (influence).

What is more, all the studies conducted locally reported findings of classroom interaction of a minimal amount in connection with teachers questioning, interactional strategies, and feedback. In the meantime, Kifle (2008) conducted the types of teacher questions and questioning strategies employed in teaching language in EFL classrooms for grade 11th English teachers and eighty students at Keranyo Alpha secondary school and Saint Marry Catholic secondary school. The study's findings suggest that $77.1 \%$ were knowledge questions, and $22.90 \%$ were comprehension questions requiring recall and short answers. Regarding their levels, the former is lower order, and the latter is middle-order questions. The study also indicates that questioning strategies that are thought to be effective for learning English in the classroom were not effectively used while the lessons were observed.

Moreover, Habtamu (2009) explored the role of EFL teachers' classroom questions for students' classroom interaction. The author selected Merafe Secondary School in Addis Ababa to achieve this purpose. Questionnaires for both grade 9 students' and teachers were also administered and used as a supplementary source of data. Based on the obtained data, Questioning is found to be the second most frequently practiced activity of the EFL classroom in the practical lesson. The EFL teachers' classroom questions is found to play the role of initiating IRF (Initiate, Response, and Feedback) patterns of classroom interaction and not going beyond that up to meaning negotiations and actual language use.

Furthermore, the problems, which will be explored here, are teacher's questions, interactional strategies, and feedback in a class. Because teacher feedback and response to students' contributions and strategies have been critical elements in classroom interaction, they have a significant effect on students' discourse and classroom interaction (Pei, 2012). In addition, some interaction strategies effectively develop students' classroom discourse and encourage their involvement in classroom interaction (Clifton, 2006). Focusing on them can be expected to show valuable findings which will add to our understanding of EFL classroom interaction and facilitate the teaching and learning process at secondary schools.

As it is noted, the types of teachers' interactional strategies need further investigation. There are limited studies on the types of teachers' interactional strategies, and no local research was conducted on teachers' Questioning, teachers' interactional strategies and teachers' feedback in EFL classes. Teachers and textbooks use either direct approaches that focus on aspects of oral contact such as turn-taking and topic management, or indirect ways that use group work, task work, and other strategies to create oral interaction settings (Richards, 1990).

Thus, having all these assumptions about speaking skills practice and findings, the present researcher finds it essential to analyse classroom interaction in the EFL speaking class of interactional strategies, interaction-oriented speaking inputs, and feedback. 
Therefore, the research questions which this study merited to answer were:

1) What types of feedback are provided to grade nine students in classroom interaction?

2) What interactional strategies do teachers use during classroom interaction?

3) What kinds of interaction-oriented speaking inputs are given in grade 9 students' textbooks?

\section{Methods}

\subsection{The Research Design}

To study this analysis of real classroom interaction in speaking class using the Walsh framework, a qualitative descriptive method was employed. A qualitative descriptive research design needs to be the design of choice when a brief description of a phenomenon is desired. It's a method that comes in handy when researchers want to know who was involved in an event, what was involved, and where it happened (Lambert, 2012).

\subsection{The Research Setting and Population of the Study}

This study was carried out in the Lalibela General Secondary School. The school is located in the town of Lalibela in the Amhara Regional State. In the first semester of Grade 9 English class at Lalibela high school, the research began. Grade nine students in the first semester of English class and four English teachers who taught English subjects took part in this study.

\subsection{Sample size and Sampling Techniques}

Meanwhile, in this study, all grade 9 English teachers (four in number) were selected purposefully altogether concerning their four sections of students. According to Lambert, nearly any purposeful sampling technique can be employed in a qualitative descriptive design when it comes to sampling. The purpose, like with any qualitative descriptive design, is to obtain cases that are considered to be rich in information to saturate the data. In addition, 357 students attended when 16 observations were conducted in 8 sections.

\subsection{Data Collection Instruments}

Qualitative data collection methods, such as interviewing, observation, and document analysis, were used for this study.

\subsection{Observation}

In this study, the observational data was collected through audio recording and counting non-verbal languages or expressions in the form of naturalistic observation. Accordingly, I conducted an observation as an observer.

\subsection{Interview}

The researcher conducted One-on-One Interviews, which is a data collection process in which the researcher asks questions and records answers from only one participant in the study at a time. To consolidate the data gathered through observation, Semistructured interviews were used for the observed classroom teachers.

\subsection{Document}

I used a grade 9 English textbook to analyse interactive curricular inputs for speaking skills. With observational or interview data, documents are ready for analysis without the need for transcription (Creswell, 2012).

\subsection{Method of Data Analysis}

After administering these research tools, the data were collected and organized. Thus, this study analysed the data gathered from classroom observation and interviews and then interpreted it descriptively. To analyze the data collected through the data collection instruments, qualitative data analysis methods were carried out for the data obtained from observation, interview, and 
document. Qualitative content analysis (Latent content analysis) was employed for these instruments. The qualitative content level analysis at the latent level is concerned with an interpretative study of the data's underlying deeper meaning (Dornyei, 2007).

One essential data analyzing tool or framework was used in this study. The Self Evaluation of Teacher Talk (SETT) instrument developed by Walsh (2006) was employed to identify the interactional strategies as the descriptive tool for the classroom transcribed data based on the coding of the 16 lesson transcripts. Despite the qualitative nature of the classroom audio recordings and audiotaped interviews, the data categorized from the transcription were quantified based on the framework.

\subsection{Data Collection Procedures}

In collecting the data, the researcher followed the following procedure. First, the researcher had a short conversation with the head of the English language department regarding the schedule of Grade 9 English lessons and the teachers assigned to teach at Lalibela secondary school. Secondly, before observation, the researcher collected data using a pre-semi structured interview protocol from four English subject teachers at this grade level. For both data gathering tools, the audio was recorded by using Samsung galaxy mobile recorder.

By utilizing the recorder, the collected data are more accurate, and the data collection becomes more precise. Then the data collected from the recording were transcribed into a written form to facilitate the researcher in analyzing them. Thirdly, the researcher conducted 16 unstructured observations in the first semester of 2013 E.C in 8 classes of grade 9 English speaking lessons. For data collection purposes, an audio-recorder was used to record the classroom interaction data in the teachinglearning process. Without audio recording, it was challenging to observe the interactional data in the classroom.

Fourth, the researcher collected the data post-semi-structured interview after completing the observation schedule. The interview aimed to complement the data collected from observation and verify the trustworthiness of the data before and after the observation. It helped to know the teachers' understanding, beliefs, opinions, experience, etc before and after observation takes place.

Fifth, all the data was transcribed after observation and interview conducted. The recorded data were carefully listened to, and the interaction patterns were transcribed and analysed. The process of translating audiotape recordings or field notes into written data is known as transcription (Creswell, 2012). The observation and the interview were written in a descriptive and narrative report. To keep the validity of the transcription into a written form, the researcher played back the recorder numerous times during the transcription. Similarly, the four teachers were recorded during the interview since this was conducted to get information from the teachers. It was done when the data obtained from the observation was considered not clear or insufficient.

Finally, document analysis was also used to complement the data not covered in the recording, such as the activities, inputs, techniques during the teaching and learning process. The document taken for analysis is the grade 9 English textbook and all the speaking tasks used as a bridge between students and teachers. Moreover, the collected data were coded according to the themes.

\section{Results And Discussion}

\section{Presentation and Analysis of Types of Feedback Provided by Teachers for Students in Speaking Classroom Interactions.}

Table 1

Types of Feedback.

\begin{tabular}{|c|c|c|c|c|c|c|c|c|c|c|}
\hline \multirow[t]{3}{*}{ Types of feedback } & \multicolumn{8}{|c|}{ Teachers } & \multirow[t]{3}{*}{ All Total } & \multirow[t]{3}{*}{$\%$} \\
\hline & \multicolumn{2}{|c|}{ Teacher 1} & \multicolumn{2}{|c|}{ Teacher 2} & \multicolumn{2}{|c|}{ Teacher 3} & \multicolumn{2}{|c|}{ Teacher 4} & & \\
\hline & $F$ & $\%$ & $\mathbf{F}$ & $\%$ & $F$ & $\%$ & $F$ & $\%$ & & \\
\hline Form focused & 102 & 85 & 191 & 84.51 & 74 & 100 & 29 & 96.67 & 396 & 88 \\
\hline Content & 18 & 15 & 35 & 15.49 & 0 & 0 & 1 & 3.33 & 54 & 12 \\
\hline Total & 120 & 100 & 226 & 100 & 74 & 100 & 30 & 100 & 450 & 100 \\
\hline
\end{tabular}


As presented in Table 1 above, teachers gave $88 \%$ of form-focused feedback. The result shows that teachers used $12 \%$ of content feedback during classroom interaction. Across the whole lesson, teacher three provided $100 \%$ of form-focused feedback, followed by $96.67 \%$ of form-focused feedback given by teacher four. In addition, teacher one also used $85 \%$ of form-focused feedback in sixteen lessons.

However, as indicated in the above table, the least result of form-focused feedback of $84.51 \%$ was provided by teacher two. The result indicated that teachers were highly provided form-focused feedback for their students. Regarding the practice of content feedback during classroom interaction, teacher two and teacher one was highly provided $15.49 \%$ and $15 \%$ of content feedback, respectively. In addition, teacher four also gave $3.33 \%$ of content feedback, whereas teacher three did not provide content feedback during the lessons.

\section{The Types of Feedbacks Provided to Grade Nine Students in Speaking Classroom Interaction.}

This transcribed qualitative data aimed to identify the types of feedback teachers used across the sixteen lessons. The finding of teachers' feedback showed that form-focused feedbacks were dominant than content feedback. Teachers' form-focused feedback concentrated on encouraging words, accepting phrases or words of students' answers, and correcting grammatical structures. The findings of form-focused feedback were popular from content feedback, but the percentage of the findings was indifferent. Suryati (2015), for example, conducted research on teachers' use of interaction tactics in English Language Teaching (ELT) at the lower secondary level. $7.9 \%$ of offering form-focused comments was found, according to the findings. The current study of formfocused feedback findings, on the other hand, found 15.49 percent.

Presentation and Analysis of Interactional Strategies Used by Teachers during the Classroom Interactions. 
Table 2

Interactional Strategies Used by Teachers.

\begin{tabular}{|c|c|c|c|c|c|c|c|}
\hline \multirow{2}{*}{$\begin{array}{l}\text { Mode and } \\
\text { pedagogical } \\
\text { goals }\end{array}$} & \multirow[t]{2}{*}{ Interactional strategies } & \multicolumn{4}{|c|}{ Frequency which occurs in } & \multirow[t]{2}{*}{ Total } & \multirow[t]{2}{*}{$\%$} \\
\hline & & $\mathrm{T} 1$ & $\mathrm{~T} 2$ & T3 & $\mathrm{T} 4$ & & \\
\hline \multirow[t]{2}{*}{ Managerial } & $\begin{array}{l}\text { A single, extended teacher } \\
\text { turn which uses explanations } \\
\text { and /or instruction }\end{array}$ & 254 & 190 & 134 & 59 & 637 & 17.66 \\
\hline & $\begin{array}{l}\text { Negotiation (clarification } \\
\text { request and confirmation } \\
\text { checks) }\end{array}$ & 41 & 35 & 64 & 21 & 161 & 4.46 \\
\hline \multirow[t]{6}{*}{ Materials } & *IRF/Non IRF patterns & $66 / 39 *$ & $64 / 79 *$ & $58 / 96 *$ & $5 / 5^{*}$ & 193/219* & $\longrightarrow$ \\
\hline & $\begin{array}{l}\text { Display/Referential } \\
\text { Questions }\end{array}$ & $101 / 23$ & $37 / 3$ & $150 / 5$ & $17 / 0$ & $305 / 31$ & $8.5 / .86$ \\
\hline & Scaffolding & 4 & 13 & 12 & 0 & 29 & .80 \\
\hline & Form focused feedback & 44 & 99 & 72 & 5 & 220 & 6.1 \\
\hline & $\begin{array}{l}\text { Negotiation (clarification } \\
\text { request and confirmation } \\
\text { checks) }\end{array}$ & 69 & 23 & 44 & 8 & 144 & 3.99 \\
\hline & Direct repair & 0 & 3 & 5 & 0 & 8 & .22 \\
\hline \multirow{8}{*}{$\begin{array}{l}\text { Skill and } \\
\text { Systems }\end{array}$} & *IRF/Non IRF patterns & 79/68* & $121 / 149 *$ & $13 / 3^{*}$ & $26 / 38 *$ & $239 / 258 *$ & $\longrightarrow$ \\
\hline & $\begin{array}{l}\text { Display/Referential } \\
\text { Questions }\end{array}$ & $162 / 17$ & $54 / 24$ & $60 / 1$ & $20 / 3$ & $296 / 45$ & $6.6 / 1.2$ \\
\hline & Scaffolding & 2 & 16 & 2 & 2 & 22 & .61 \\
\hline & Extended teacher turns & 45 & 94 & 39 & 17 & 195 & 5.4 \\
\hline & $\begin{array}{l}\text { Teachers' } \\
\text { echo/completion/interruption }\end{array}$ & $63 / 26 / 17$ & $106 / 55 / 126$ & $42 / 20 / 69$ & $17 / 2 / 33$ & $228 / 103 / 245$ & 15.97 \\
\hline & Form focused feedback & 58 & 91 & 2 & 24 & 175 & 4.9 \\
\hline & $\begin{array}{l}\text { Negotiation(clarification } \\
\text { request and confirmation } \\
\text { checks) }\end{array}$ & 149 & 48 & 28 & 11 & 236 & 6.54 \\
\hline & Direct repair & 8 & 26 & 7 & 4 & 45 & 1.25 \\
\hline \multirow{8}{*}{$\begin{array}{l}\text { Classroom } \\
\text { Context }\end{array}$} & Extended learner turn & 4 & 29 & 0 & 2 & 35 & .97 \\
\hline & Short teacher turn & 32 & 84 & 8 & 10 & 134 & 3.71 \\
\hline & Direct repair & 0 & 0 & 2 & 0 & 2 & .05 \\
\hline & Content feedback & 18 & 35 & 0 & 1 & 54 & 1.5 \\
\hline & Referential Questions & 61 & 17 & 0 & 20 & 98 & 2.71 \\
\hline & Scaffolding & 2 & 0 & 0 & 1 & 3 & .08 \\
\hline & $\begin{array}{l}\text { Negotiation(clarification } \\
\text { request and confirmation } \\
\text { checks) }\end{array}$ & 81 & 43 & 11 & 21 & 156 & 4.32 \\
\hline & & 1281 & 1251 & 777 & 298 & 3607 & \\
\hline
\end{tabular}


NB:-

- The IRF/non-IRF patterns are not added to the total number of teacher talk because they have been counted already in display/referential questions.

- IRF stands for Initiation Response Feedback

As indicated in Table 2 above, the result of a single, extended teacher turn that uses explanations and instruction was $17.66 \%$ in managerial mode. In addition, $4.46 \%$ of teachers' talk were clarification requests and confirmation checks. It is given away those teachers were more devoted to facilitating the classroom, giving instruction, and transferring information and teachers also provided clarification and confirmation checks.

In material mode, the result of the total pattern of IRF and Non-IRF was identified as 195 and 219 , respectively. This shows that the student's response was not evaluated immediately. Teachers asked $8.5 \%$ of display questions in material mode. However, it was identified that teachers also provided $0.86 \%$ of referential questions. The result shows that display questions were more popular than referential questions. The occurrence of scaffolding in material mode was $0.8 \%$. This shows that teacher's clue was given less emphasis during classroom interaction. The following excerpts show that teachers extended the students' answers by giving clues.

\section{Excerpt 1}

( teacher -1 ; describing places)

T1:...

S15: Nech sar national park Adiss Ababa.

T1: Yes, yes what..

S15: Nech sar national park Adiss Ababa

T1 is found ....

S15: Adiss Ababa.

T1: Adiss Ababa ... Nech sar national park ...is it ehhh...Nech sar?

Excerpt 2: (teacher - 2; describing places)

T2: You, please be quite ..the other students ...be quite ..be quite ehhh.....

S51:This is the picture of Nech sar National Park.

T2: ehhh...Nech sar .. .... Nech sar National Park

S51: Nech sar National Park

T2: This picture shows ...

S51: This picture shows zebra.

T2: Zebra ...very good ehhh...

\section{Excerpt 3}

(teacher-4; Giving direction)

T4: Would you tell me where the stadium is ,please? 
- Ok.

S2: near the sport club.

T4: ehhh...

S2: Near of the sports club ...number three...

T4: Near of the sports club.

- It represents the ehh...letter or number....number.

S2: three

T4: Number three from the map.

S2: Yes.

T4: good,good ehhh...

Teachers also gave feedback to their students to facilitate interaction during the whole lesson. Teachers gave $6.1 \%$ of formfocused feedback, and feedback focused on accepting answers and correcting some grammatical structures. The following excerpts were extracted from observations during classroom interactions.

Excerpt 4 :(Teacher -1 ; class survey)

T1: to be what? what is your hobby for the future?

S17: Engineer

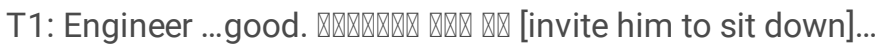

Excerpt 5 (Teacher - 2; class survey)

T2: ehhh...

S7: I am address Lalibela.

T2: ehhh...my addres is Lalibela .

- ok that is right.

Excerpt 7: (Teacher -3 ; describing places)

T3: Who can describe again the first one ...? Yes.

S2: This picture is Harar. The pictures shows old city of Harar.

T3: The picture shows the old city.

Very good

Excerpt 6: (Teacher 4: what I like doing at my free time activity)

T4: Make adiary or activity or one or more

S9: I am get up

T4: I get up 
In material mode, the occurrences of negotiation (clarification and confirmation check) and direct repair were $3.99 \%$ and $0.22 \%$, respectively. The result shows that direct repair was the least occurrence in material mode. The following excerpts indicate how the teacher repaired incorrect acts through sixteen lessons.

Excerpt 7: (Teacher 1: describing places)

SS: wild animals.

T1: wild animals live in ...live in there.that....ehhh

Excerpt 8: (Teacher 2: describing places.)

S12: The pictures shows traditional foods.

T2:The picture shows traditional food ...

Excerpt 9:(Teacher 3: giving direction)

S18: and go straight line

T3: go straight along. The road in to...

S18: government road..

Excerpt 10 :(Teacher 4- Describing places)

S8:Language; more eighteen ehhh...more language for Ethiopia ...Amharic ...ehhh...Tigray ehhhh...oromiya.

T4: Tigrigna ,Oromifa

In skill and system mode, non-IRF and IRF patterns were 258 and 239, respectively. As inferred, non-IRF patterns were more dominant than IRF patterns. Display questions were $6.6 \%$ in this mode, but referential questions were $1.2 \%$. Another common feature in skill and system mode was scaffolding. The occurrence of scaffolding was $0.61 \%$. Teachers hardly devoted the time helping their students by giving extended clues to correct themselves. The following Excerpt shows how teachers helped students to correct their answers.

Excerpt 11 :(Teacher 1: class survey)

T1: how many brothers do you have? I have....

S12: I have two brother.

T1: I have ...ehhh?

S12: I have two brothers and one sister.

T1: I have ...one...

S12:two brothers.

T1:and...

S12: one sister.

T1: one sister...

\section{Excerpt 12}


(Teacher - 4; what I like doing at my free time activity)

T4: Make adiary or activity or one or more

S9: I am get up

T4: I get up

S9: I get up twelve o'clock

The percentage of teachers' extended turns in skill and system mode was $5.4 \%$. This interactional strategy was used to establish students' knowledge during classroom interaction. The following Excerpt indicates teachers extended turns in skill and system mode.

\section{Excerpt 13}

(Teacher - 4; describing places)

T4: Ethiopia...

S7: Ethiopia has many languages.

T4: ehhh...

S7: churches ; Ethiopia has many churches example ;Lalibela, Debredamo,Gishen, etc...

- Mosque-....ehhh...example .nejashi mosque...

T4 : Al - Nejashi....

S7: al ...

T4: Al- Nejashi...al..

S7: Al-nejashi mosque...

- Historical site - Ethiopia has ehh...have historical site ...example ;

T4: Many historical sites

S7: sites ;Example Axum, Lalibela, Gondar, Blue Nile Falls, Harar, sofuomor...

T4: ok.

The next feature in the skills and system mode was teachers' echo/completion /interruption, which displayed students' contribution by repeating, completing, and interrupting it. The percentage of occurrence of the teacher echo/ completion /interruption was $15.97 \%$. This was the highest occurrence in skill and system mode. Finally, the occurrences of the last three subcategories of skill and system mode of form-focused feedback, clarification and confirmation checks, and direct repair were $4.9 \%, 6.54 \%$, and $1.25 \%$, respectively. The following Excerpts are an example of direct repair from the practical lessons.

\section{Excerpt 14}

(Teacher - 1; describing places)

S13: I have two brother no sister.

T1: you have how many brother? 
S13: two brother

T1: two brothers ok...ehhh

\section{Excerpt 15}

(Teacher - 2; class survey)

S12: what read or Tv programs do you listen or watch?

T2: what radio

Excerpt 16: (Teacher - 3: Giving direction)

S24: can you tell me sports club?

T3: can you tell me where the sports club is?

\section{Excerpt 17}

(Teacher 4; what I like doing at my free time activity)

S9: I am go to school one hour..one o'clock

T4: always

S9: always

In the classroom context, $0.9 \%$ of occurrences of extended learner turns were found. As demonstrated in table 2 , short teacher turn was $3.71 \%$. The result shows that teachers' content feedback and direct repairs were $1.5 \%$ and $0.05 \%$, respectively. $2.71 \%$ of referential questions were found in this mode. The occurrence of scaffolding was $0.08 \%$.

Moreover, clarification and confirmation checks were $4.32 \% .4 .32 \%$ of clarification and confirmation has the most significant percentage, followed by $3.71 \%$ short teacher turn. However, a few direct repairs and extended learners' turns were identified across the sixteen lessons. The following excerpts show the extended learners turn in the mode of the classroom context.

\section{Excerpt 18}

(Teacher - 1; asking politely )

S12: could you tell me ehhh... could you tell me Lalibela bus station?

S13: near to Lalibela supermarket .

S12: where is Abay Bank?

\section{Excerpt 19}

(Teacher - 2;class survey)

S21: what jobs do you do at home?

S22: I wash dish.

S21: what sports do you play?

S22: I play volley ball. 
S21: what radio or Tv programs do you listen or watch?

S22: I watch Black Mask.

S21: do you have any hobbies not sports?

S22:my hobby is [ inaudible]...

\section{Excerpt 20}

(Teacher - 4; describing places)

S5: mosques...[inaudible]..mosques ...ras desta

- Historical- ehhh...Ethiopia have many historical sites for example;Lalibela, Ras dashn,Axum,Gondar,Harar...

S6: Ethiopia have many languages example Amharic ,Oromo ,Afar Wolayta ...church...

It can be concluded that, among other modes, classroom context had not been emphasized by teachers through sixteen lessons. Hence, students had not been given opportunities to personalize the lesson's content. In addition, the result indicated that skill and system mode was highly practiced and followed by managerial mode. Whereas the result of occurrences of classroom context was the least found. Moreover, the most frequently used interactional strategies were a single, extended teacher turn which uses explanations/instruction, clarification request and confirmation checks, teacher's echo/completion/interruptions, display questions, form-focused feedback, and Non -IRF /IRF patterns. However, interactional scaffolding strategies, content feedback, direct repair, and extended learners' turns were rare.

\section{The Types of Interactional Strategies Used by the Teachers during the Classroom Interaction.}

The findings of types of interactional strategies used by the teachers during the classroom interaction have prevailed under the umbrella of four modes. These modes were managerial mode, material mode, skill and system mode, and classroom context mode. In managerial mode, the findings of interactional strategies of a single, extended teacher turn that uses explanations and /or instruction took many interactional strategies of asking clarification requests and confirmation checks.

The second findings interactional strategies left to material modes. Regarding the interactional strategies in material mode, interactional strategies of display questions, a pattern of Non-IRF and IRF, form-focused feedback, and negotiation (clarification request and confirmation checks) were the largest number of the occurrences in order. In contrast, referential questions scaffolding and direct repair were the least found during classroom interaction.

Thirdly, the findings of interactional strategies of teachers' echo/completion /interruption, display questions, the pattern of NonIRF and IRF, clarification request and confirmation checks, extended teachers turn, and form-focused feedback was the highest percentage in skill and system mode. However, the findings of the interactional strategy of scaffolding were found least. The excessive use of these interactional strategies hinders students from interacting in the classroom. Finally, few occurrences of interactional strategies were found in classroom context modes. The findings of interactional strategies of negotiation (clarification request and confirmation checks) and short teachers' turn took the highest percentages of the occurrences through direct repair, scaffolding, and short teachers' turn were hardly found.

The data revealed that in Lower Secondary Schools, much of the teacher-student contact was focused on material, skill, and system modes(Suryati, 2015). Whereas, the current study's findings indicated much of interaction in the classroom was different and focused on skill and system and managerial mode. In Suryati's finding, initiation response feedback (IRF) patterns, display questions (38 percent), teacher echo (17.3 percent), and extended teacher turns (27.2 percent) were the most common strategies, whereas students' extended turns were rare. However, interactional strategies of $19.32 \%$ of negotiation (clarification request and confirmation checks) and $17.66 \%$ of a single, extended teacher turn that uses explanations and /or instruction display questions. 
In the current study, the most dominant interactional strategies were Non-IRF, IRF, $15.97 \%$ of teachers echo, and $10.97 \%$ of formfocused feedback. In contrast, extended learner turn, scaffolding, content feedback, and direct repair were rare. Moreover, Suryati's (2015) study showed that IRF patterns dominate teacher-student interaction, with 629 IRF patterns and only 99 occurrences of Non-IRF patterns. However, the patterns of dominant teacher-student interactions were Non-IRF patterns consisting of 477 , while the occurrences of IRF patterns were 432 found in the current study.

Presentation and Analysis of Kinds of Interaction Oriented Speaking Inputs Given in Grade Nine Student Textbook. 
Table 3

Speaking Inputs in Grade 9th English Textbook.

\begin{tabular}{|c|c|c|c|c|c|}
\hline Unit & Unit Topic & page & Part & Speaking lesson topic & $\begin{array}{l}\text { Number of } \\
\text { tasks }\end{array}$ \\
\hline \multirow[t]{3}{*}{ Unit one } & \multirow[t]{3}{*}{ Learning to learn } & 9 & A1.10 & Pronunciation practice & 1 \\
\hline & & 12 & B1.2 & Class survey & 3 \\
\hline & & 14 & B1.6 & New school advice & 3 \\
\hline \multirow[t]{7}{*}{ Unit two } & \multirow[t]{7}{*}{ Places to Visit } & 20 & A2.3 & Describing places & 1 \\
\hline & & 23 & A2.8 & Class survey & 4 \\
\hline & & 24 & A2.10 & Giving direction & 4 \\
\hline & & 25 & A2.11 & Asking politely & 2 \\
\hline & & 27 & B2.2 & Future plans & 1 \\
\hline & & 31 & B2.6 & Pronunciation practice & 2 \\
\hline & & 35 & B2.11 & Pronunciation endings & 2 \\
\hline \multirow{4}{*}{$\begin{array}{l}\text { Unit } \\
\text { three }\end{array}$} & \multirow[t]{4}{*}{ Hobbies and rafts } & 43 & A3.7 & What I like doing in my free time & 3 \\
\hline & & 44 & A3.8 & Class survey & 2 \\
\hline & & 47 & A3.10 & Pronunciation practice & 1 \\
\hline & & 48 & B3.1 & Agreeing and disagreeing & 2 \\
\hline \multirow[t]{4}{*}{ Unit four } & \multirow[t]{4}{*}{ Food and health } & 64 & A4.4 & Proverbs & 1 \\
\hline & & 67 & A4.7 & Healthy and unhealthy foods & 2 \\
\hline & & 71 & B4.1 & Class survey & 3 \\
\hline & & 76 & B4.7 & Pronunciation -ei and ie & 3 \\
\hline \multirow[t]{4}{*}{ Unit five } & \multirow[t]{4}{*}{ HIV and AIDS } & 82 & A5.3 & Discussion about AIDS & 4 \\
\hline & & 84 & A5.6 & Expressing sympathy & 3 \\
\hline & & 86 & A5.9 & Advice for younger children & 2 \\
\hline & & 88 & B5.1 & Problem pictures & 1 \\
\hline \multirow[t]{5}{*}{ Unit six } & \multirow[t]{5}{*}{ Media, TV and Radio } & 100 & A6.4 & Describing people & 2 \\
\hline & & 103 & A6.9 & Expressing opinion & 2 \\
\hline & & 107 & B6.2 & Radio and TV programs & 3 \\
\hline & & 111 & B6.7 & Who is your favorite celebrity? & 3 \\
\hline & & 112 & B6.9 & Word stress & 1 \\
\hline \multirow{4}{*}{$\begin{array}{l}\text { Unit } \\
\text { seven }\end{array}$} & \multirow[t]{4}{*}{ Cities of the future } & 121 & A7.4 & Comparing cities & 2 \\
\hline & & 125 & A7.10 & A proud old man & 2 \\
\hline & & 127 & B7.1 & Ethiopia - past and present & 5 \\
\hline & & 131 & B7.5 & Predicting the future & 2 \\
\hline \multirow{2}{*}{$\begin{array}{l}\text { Unit } \\
\text { eight }\end{array}$} & \multirow[t]{2}{*}{ Money and finance } & 140 & A8.7 & Matching money & 2 \\
\hline & & 141 & A8.8 & Dialogue in a bank & 6 \\
\hline
\end{tabular}




\begin{tabular}{|c|c|c|c|c|c|}
\hline Unit & Unit Topic & page & Part & Speaking lesson topic & $\begin{array}{l}\text { Number of } \\
\text { tasks }\end{array}$ \\
\hline & & 144 & A8.11 & Discussion & 3 \\
\hline & & 146 & B8.2 & Expressing surprise & 2 \\
\hline & & 148 & B8.4 & Winning the lottery & 1 \\
\hline \multirow[t]{7}{*}{ Unit nine } & \multirow{7}{*}{$\begin{array}{l}\text { People and traditional } \\
\text { culture }\end{array}$} & 157 & A9.4 & Traditional objects & 1 \\
\hline & & 157 & A9.5 & $\begin{array}{l}\text { What do you know about Ethiopian culture and } \\
\text { traditions? }\end{array}$ & 2 \\
\hline & & 158 & A9.7 & Adverbs of manner & 1 \\
\hline & & 160 & A9.9 & Expressing opinion & 2 \\
\hline & & 160 & A9.10 & Debate & 7 \\
\hline & & 163 & B9.1 & Parts of the body & 3 \\
\hline & & 165 & B9.3 & Asking for clarification & 3 \\
\hline \multirow[t]{5}{*}{ Unit ten } & \multirow{5}{*}{$\begin{array}{l}\text { Newspapers and } \\
\text { magazines }\end{array}$} & 178 & A10.3 & Agreeing, disagreeing and giving opinions & 3 \\
\hline & & 181 & A10.5 & Pronunciation practice & 2 \\
\hline & & 182 & A10.8 & Debate & 3 \\
\hline & & 183 & A10.9 & Pronunciation - word stress & 4 \\
\hline & & 188 & B10.6 & Newspaper interview & 1 \\
\hline \multirow{3}{*}{$\begin{array}{l}\text { Unit } \\
\text { eleven }\end{array}$} & \multirow[t]{3}{*}{ Endangered animal } & 194 & A11.4 & Talking about animals & 2 \\
\hline & & 199 & A11.11 & Endangered animals & 4 \\
\hline & & 204 & B11.5 & Group discussion & 3 \\
\hline \multirow{5}{*}{$\begin{array}{l}\text { Unit } \\
\text { twelve }\end{array}$} & \multirow{5}{*}{$\begin{array}{l}\text { Stigma and } \\
\text { discrimination }\end{array}$} & 209 & A12.3 & Discrimination & 2 \\
\hline & & 210 & A12.5 & Helping the disabled & 2 \\
\hline & & 212 & A12.9 & Pronunciation - polysyllabic words & 4 \\
\hline & & 216 & B12.3 & Are these saying true? & 2 \\
\hline & & & & Total Tasks & 137 \\
\hline
\end{tabular}

As indicated in table 3, the number of interactional speaking input activities in the grade nine English textbook is 137, and these activities are listed under twelve units. Among these interactive speaking activities, 35 interactive speaking activities were delivered across sixteen speaking lessons. Meanwhile, the researcher counted those teachers were left with 13 interactive speaking activities during the whole observations were made. The organization of speaking topics and speaking activities across twelve units seems cyclic. Moreover, the speaking activities in grade nine English textbooks allow students to speak and facilitate classroom interaction. However, the teachers have never adapted additional inputs that offer speaking skills, as the researcher learned from the following extracts.

T1: ehh... I am I have not adapt this material but I want to change or the approach to provide simple ..simple way or I give a narrative.

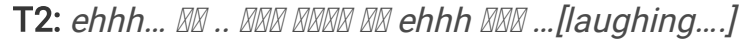

T3: which material? ehhh... Yes I tried to teach them 
T4: their locality... The locality do you localized it? do you localize the materials? as much as I can as much as I can and according to our student interest depending on the situation because mostly the text book is more trivial activities are there. ya... ya... we must localize. the topic or any given points according to our environment .... when I was teach and giving direction ....Adebabay to Shimbirima .....

\section{Identifying Kinds of Interaction Oriented Speaking Inputs Given in Grade Nine Student Textbook.}

The findings of interaction-oriented speaking inputs were distributed across twelve units in the grade nine English textbook. The most significant number of speaking activities were listed under unit nine and unit two of 19 and 16, respectively. Whereas the number of interactional speaking activities 7 of units one and twelve (6) were the least found.

Moreover, there were 35 interactive speaking activities across sixteen speaking lessons, but teachers left 13 interactive activities during classroom interactions. This indicated that teachers skipped $37.14 \%$ of inputs critical ingredients in practicing the intended speaking skills. Even though the number of speaking inputs/activities in each unit across the textbook were 11 on average, the content of these activities was also organized from simple to complex and cyclic. Concerning adapting learners' textbooks, teachers were asked through interviews and replied they were not engaged in adapting materials

\section{Conclusions}

Regarding types of feedback provided to grade nine students in speaking classroom interaction, form-focused feedback was more dominant than content feedback. Teachers' form-focused feedback concentrated on encouraging words, accepting phrases or words of students' answers, and correcting grammatical structures.

As types of interactional strategies used by the teachers during the classroom interaction in managerial mode, teachers highly used a single, extended teacher turn that includes explanations and /or interactional instruction strategy in classroom interaction across the whole lessons. Regarding the interactional strategies in material mode, teachers also used excessive display questions, a pattern of Non-IRF and IRF, form-focused feedback, and negotiation. (Clarification request and confirmation checks).

In addition, interactional strategies of teachers' echo/completion /interruption, display questions, a pattern of Non-IRF and IRF, clarification request and confirmation checks, extended teachers turn, and teachers dominantly used form-focused feedback in a mode of skill and system during classroom interaction. Teachers also dominantly used interactional strategies of negotiation (clarification request and confirmation checks), and short, teachers turned in the mode of the classroom context. Moreover, the teacher used a single, extended teacher turn which uses explanations and /or instruction from all categories of interactional strategies.

Finally, skill and system mode were excessively used from the other modes by teachers because teachers used many numbers of utterances of display questions, pattern IRF, teachers echo, negotiation (clarification request and confirmation checks), formfocused feedback, and extended teachers turn. As regards identifying kinds of interaction-oriented speaking inputs given in the grade nine student textbook, many numbers of interactive speaking activities were delivered by teachers as the students' textbooks presented accordingly. Teachers did not deliver few interactive activities appropriately.

\section{Recommendations}

In light of the study's significant findings and the conclusions are drawn, the following recommendations were suggested to improve classroom interaction to develop a speaking skill for further research. Firstly, teachers' excessive use of form-focused feedback provided using word usage, and explicit corrective feedback should be replaced by content feedback focused on the message. Teachers should also recognize that effective feedback gives students the information necessary for understanding during classroom interaction and what they need to do next.

Secondly, to create effective classroom interaction to develop students speaking skills, it is suggested that all teachers be aware of the effectiveness and usages of interactional strategies during speaking lessons. All teachers should focus on the mode

Page $17 / 19$ 
classroom context of interactional strategies that enhance students' oral communicative competence. Educational practitioners should also consider providing classroom interactional strategies that are more effective in developing students speaking skills.

Thirdly, considering textbooks have positive and vital roles in day-to-day language teaching, all teachers should deliver interactive speaking activities during classroom interaction. Unless teachers fully provide interactional speaking activities that textbooks comprise during classroom interaction, textbooks might not serve as a media that teachers and pupils communicate to forward the teaching and learning process. Additionally, researchers mainly recommend investigating input and interaction, teachers' attitudes, and code-switching in Ethiopian EFL contexts.

\section{List Of Abbreviations}

EFL

English as a Foreign Language

SETT

Self Evaluation of Teacher Talk

IRF

Initiation-Response-Feedback

ELT

English Language Teaching

\section{Declarations}

\section{Availability of data and materials}

The transcribed data used to support the findings of this study have been deposited and accessed in the FAIRsharing.org repository (https://fairsharing.org/users/6247). This transcribed data will serve ONLY as a supplementary file for the main study.

\section{Competing interests}

The author declares no competing interests

\section{Funding}

This study did not receive any funding in any form.

\section{Authors' contributions}

The author wrote, prepared, analysed, interpreted, and reviewed the manuscript.

\section{Ethics approval and consent to participate}

Not applicable

\section{Consent for participation}

Not applicable

\section{Acknowledgements}

I would like to express my heartfelt gratitude to all grade nine English language teachers, students, and members of the English department at St. Lalibela Secondary School for their enthusiastic cooperation in providing me with all necessary departmental support as well as their participation as core participants in the study.

\section{Authors' information}


Sisay is a PhD candidate (TEFL) at Bahir Dar University in Ethiopia. He earned his TEFL Master's degree from BDU. He also received his second Master's degree in project planning and management from Debre Markos University jointly YOM.. He also earned a Bsc in Computer Science from Bahir Dar University, Bahir Dar Institute of Technology. He has been teaching for the last 17 consecutive years beginning from primary to tertiary levels.

\section{References}

1. Clifton, J. (2006). Facilitator talk. ELT journal, 60(2), 142-150.

2. Creswell, J. (2012). Educational Research: Planning, Conducting, and Evaluating Quantitative and Qualitative Research. (4th Ed.). Boston: Pearson.

3. Dörnyei, Z. (2007). Research methods in applied linguistics.

4. Habtamu, G. (2009). The Role of Teachers Questions in EFL Classroom Interaction. Unpublished MA Thesis. Ababa Ababa: Addis Ababa University.

5. Kifle, A. (2008). A Study on the Types of Teacher Questions and Questioning Strategies: The Case of Two Private Secondary Schools in Addis Ababa. Unpublished MA Thesis. Ababa Ababa: Addis Ababa University.

6. Lam, T. S. (2003). English Classroom Interaction in Hong Kong: Patterns and Perspectives from Secondary School Junior Students (Doctoral dissertation, Chinese University of Hong Kong).

7. Lambert, V. A., \& Lambert, C. E. (2012). Qualitative descriptive research: An acceptable design. Pacific Rim International Journal of Nursing Research, 16(4), 255-256.

8. Liu, H., Zhao, Y., Qin, B., \& Liu, T. (2010). Comment Target Extraction and Sentiment Classification. Journal of Chinese Information Processing, 24(1), 84-88.

9. Pei, M. (2012). Teacher's Discoursal Strategies in Providing Positive Feedback to Student Responses: A Study of Four English Immersion Teachers in People's Republic of China. International education, 41(2), 7.

10. Rashidi, N., \& Rafieerad, M. (2010). Analysing patterns of classroom interaction in EFL classrooms in Iran. Journal of Asia TEFL, $7(3)$.

11. Richards, J. (2001). Teaching Listening and Speaking: From Theory to Practice. New York: Cambridge University Press.

12. Richards, J. C. (1990). Conversationally Speaking: Approaches to the Teaching of Conversation. In Jack. C. Richards. The Language Teaching Matrix. New York: Cambridge University Press. 67-85.

13. Suryati, N. (2015). Classroom interaction strategies employed by English teachers at lower secondary schools. TEFLIN Journal, 26 (2), 247-264.

14. Tsui, A.B. (1985). Analysing input and interaction in second language classrooms, RELC Journal, 16(1): 8-32.

15. Walsh, S. (2006). Talking the talk of the TESOL classroom. ELT journal, 60(2), 133-141.

\section{Supplementary Files}

This is a list of supplementary files associated with this preprint. Click to download.

- Supplementarydocs.rar 